\title{
Gene editing
}

Recent patents related to CRISPR-based gene editing, disease treatment and methods for targeting nucleic acids.

\begin{tabular}{ll} 
Patent number & Description \\
\hline US 10,676,735 & $\begin{array}{l}\text { Methods of using CRISPR/Cas9-based epigenomic editing } \\
\text { systems for high-throughput screening of regulatory eleme } \\
\text { function. }\end{array}$ \\
US 10,669,559 & $\begin{array}{l}\text { Methods and vectors for rational, multiplexed manipulation } \\
\text { of chromosomes within open reading frames (for example, } \\
\text { protein libraries) or any segment of a chromosome in a cell } \\
\text { population of cells, in which various CRISPR systems are us }\end{array}$ \\
US 10,669,540 & $\begin{array}{l}\text { Systems, methods and compositions for targeting nucleic } \\
\text { acids. In particular, non-naturally occurring or engineered } \\
\text { DNA- or RNA-targeting systems comprising a novel DNA- } \\
\text { or RNA-targeting CRISPR effector protein and at least one } \\
\text { targeting nucleic acid component like a guide RNA. }\end{array}$
\end{tabular}

US 10,590,415 Engineered Class 2 CRISPR-Cas-associated discontinuous first-stem nucleic-acid targeting nucleic acids, nucleoprotein complexes comprising these nucleic acids, and compositions thereof. Also, methods for making and using the Class 2 CRISPR-Cas-associated discontinuous first-stem nucleic-acid-targeting nucleic acids, nucleoprotein complexes comprising such nucleic acids, and compositions thereof.

US 10,369,232 Compounds, structures, compositions and methods for therapeutic guide molecules that direct CRISPR gene editing. A guide molecule for directing gene editing can be allele selective or disease-allele selective, and can exhibit reduced off-target activity. A guide molecule can be composed of monomers, including UNA monomers, nucleic acid monomers and modified nucleotides, wherein the compound is targeted to a genomic DNA. The guide molecules can be used as active ingredients for editing or disrupting a gene in vitro, ex vivo or in vivo.

US 10,279,014 A method of eliminating the risk of JCV activation in a subject undergoing immunosuppressive therapy, by administering an effective amount of a gene-editing composition directed toward at least one target sequence in the JCV genome, cleaving the target sequence in the JCV genome, disrupting the JCV genome, eliminating the JCV infection, eliminating the risk of JCV activation, and treating the subject with an immunosuppressive therapy.

US 10,253,312 CRISPR/Cas-related compositions and methods for treatment of Leber's congenital amaurosis 10.

US 9,970,030 Methods for use with Type II CRISPR-Cas9 systems for increasing Cas9-mediated genome engineering efficiency. The methods can be used to decrease the number of off-target nucleic acid double-stranded breaks and/or to enhance homology-directed repair of a cleaved target nucleic acid.

\begin{tabular}{lll} 
Assignee & Inventor & Date \\
\hline $\begin{array}{l}\text { Duke University } \\
\text { (Durham, NC, USA) }\end{array}$ & $\begin{array}{l}\text { Gersbach CA, } \\
\text { Crawford GE, }\end{array}$ & $6 / 9 / 2020$ \\
& $\begin{array}{l}\text { Reddy TE, } \\
\text { Klann TS }\end{array}$ & \\
The Regents of the & Garst A, Gill RT & $6 / 2 / 2020$
\end{tabular}

University of Colorado

(Denver, CO, USA)

The Broad Institute

(Cambridge, MA, USA),

Massachusetts Institute of

Technology (Cambridge,

MA, USA), President and

Fellows of Harvard College

(Cambridge, MA, USA)

Caribou Biosciences

(Berkeley, CA, USA)

Zhang $\mathrm{F}$,

$6 / 2 / 2020$

Zetsche B,

Slaymaker I,

Gootenberg J,

Abudayyeh $\mathrm{OO}$

Donohoue PD,

May AP

$3 / 17 / 2020$

Arcturus Therapeutics

(San Diego, CA, USA)

Chivukula P,

$8 / 6 / 2019$

Wilkie-Grantham R,

Tachikawa K

Excision BioTherapeutics (Philadelphia, PA, USA),

Temple University

(Philadelphia, PA, USA)

Khalili K,

$5 / 7 / 2019$

Malcolm T, Kohn KI

Editas Medicine

(Cambridge, MA, USA)

Maeder ML,

4/9/2019

Caribou Biosciences

(Berkeley, CA, USA)

Bumcrot DA, Shen S

Cameron PS,

$5 / 15 / 2018$

van Overbeek $M$

Source: United States Patent and Trademark Office (http://www.uspto.gov).

Published online: 8 July 2020

https://doi.org/10.1038/s41587-020-0599-8 